\title{
ATAXIA TELANGIECTASIA: A CASE REPORT
}

\author{
ISLAM MI ${ }^{1}$, HOQUE SKA ${ }^{1}$, ISLAM MT ${ }^{1}$, SALEH ASM ${ }^{2}$, SAHA NC ${ }^{3}$, RAHMAN AKM $^{1}$, ANWAR S $^{3}$, \\ BANERJEE $M^{4}$
}

\begin{abstract}
:
Ataxia Telangiectasia (AT) is a rare, neurodegenerative disease that affects many parts of the body and causes severe disability is characterized by progressive Cerebellar ataxia, oculocutaneous telangiectasia, and recurrent respiratory and sinus infections. AT is caused by a defect in the ATM gene, which is responsible for recognizing and correcting errors in duplicating DNA when cells divide, and in destroying the cells when the errors can not be corrected. A 10 years old girl who is the first issue of non consanguineous parents completely immunized according to EPI schedule was admitted to Dhaka Medical College Hospital, Dhaka, on 26.01.2010 with the complaints of generalized weakness and difficulty to walk from the 6th year. The patient has one younger sister of 7 years old who has such complaints. On examination the patient was found mildly anemic with congestions in both eyeballs that is radiating from the both corners to limbus. The patient was conscious and cooperative. Cranial nerves were intact. There were hypotonia which was more marked in lower limbs with diminished jerks and flexor plantar reflexes. Gait was wide based and ataxic. She was diagnosed as a case of AT. This case is presented as academic interest.
\end{abstract}

Key words: Ataxia Telangiectasia (AT), neurodegenerative disease.

J Dhaka Med Coll. 2010; 19(1) : 69-71.

\section{Introduction:}

The first case described in the literature was a 9-year-old child with progressive cerebellar ataxia and bilateral oculocutaneous telangiectasia reported in 1941 by Madame Louis-Bar. Initially known as the Louis-Bar syndrome, the term ataxia-telangiectasia was introduced in 1958 by Boder et al, who recorded the clinical features and recognized the familial incidence proposing an autosomal recessive mode of inheritance for the disease ${ }^{1}$. The disease is sometimes referred to as BoderSedgwick syndrome. The ataxia-telangiectasia mutated (ATM) kinase initiates a wellcharacterized response to DNA damage, resulting in arrest of cell-cycle, DNA repair, or apoptosis ${ }^{2-5}$. Mutations in the ATM gene, though tolerated, result in the fatal childhood disorder ataxia-telangiectasia (AT), characterized by symptoms including predisposition to cancer, ataxia due to progressive cerebellar degeneration, immunodeficiency, and telangiectasias (spider veins $)^{2-5}$. ATM signaling is required to sense and initiate repair of DNA double-strand breaks. Therefore, nuclear genomic instability resulting from loss of this function is regarded as a major mechanism underlying the pathology of A-T ${ }^{3-6}$. However, this disease presents with a wide-array of symptoms, not all of which are readily explained by nuclear genomic instability, and study of cell and animal models of $\mathrm{A}-\mathrm{T}$ has led to much speculation about additional pathogenic mechanisms ${ }^{7}$. One such mechanism for which there is substantial experimental evidence is oxidative stress $^{8-12}$. How ATM is involved in oxidative stress management remains unclear as do other potential roles in cellular homeostasis in the absence of DNA damage.

\section{Case Report:}

A 10 years old girl who is the first issue of non consanguineous parents completely immunized according to EPI schedule was admitted to Dhaka Medical College Hospital,

1. Assistant Professor. Department of Paediatrics. Dhaka Medical College \& Hospital. Dhaka.

2. Postgraduate trainee. Department of Paediatrics. Dhaka Medical College Hospital. Dhaka.

3. Associate Professor. Department of Paediatrics, Dhaka Medical College \& Hospital. Dhaka.

4. Assistant Professor. Department of Neonatology, Dhaka Medical College \& Hospital, Dhaka.

Correspondence: Dr. Md. Imnul Islam. 


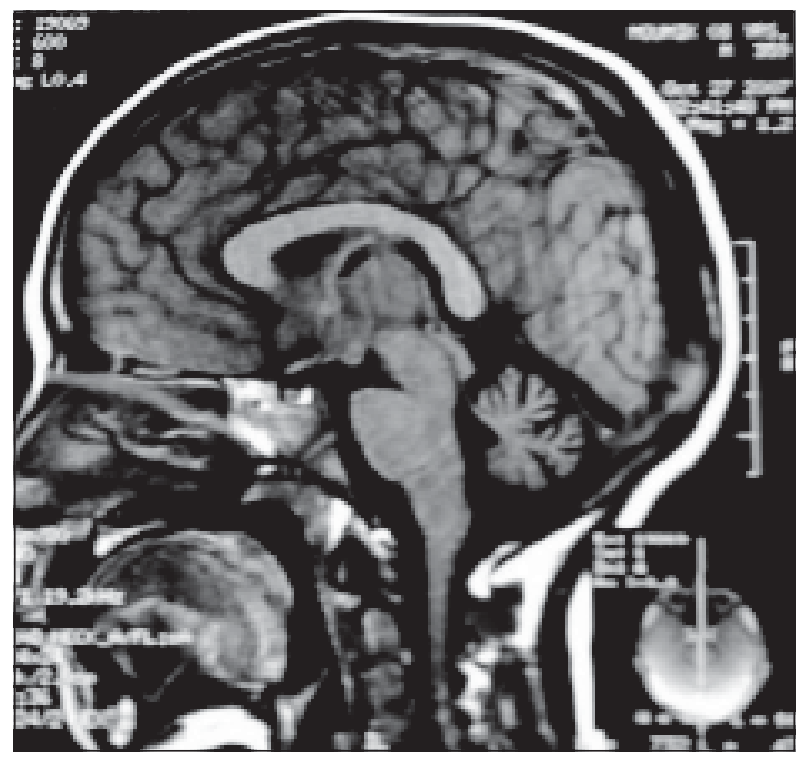

Fig.-1: MRI of brain showing Cerebellar atrophy with trifoliate appearence.

Dhaka, on 26.01.2010 with the complaints of generalized weakness and difficulty to walk from the 6 th year. The patient initially could try to walk but later on she fell on the ground as she developed imbalance in walking that gradually involved also in standing capacity within one month.

She also developed congestions of the conjunctiva that has appeared at age 7 years. The congestions is first noted in the interpalpebral bulbar conjunctiva away from the limbus. The patient has no other significant past illness except frequent respiratory illness since birth.

Her birth history is uneventful but she achieved her developmental milestones delayed. She attained her sitting at the age of 2 years and walking and standing at the age of 3 and 4 years respectively. The patient has one younger sister of 7 years old who has such complaints. On examination, the patient was found mildly anemic with congestions in both eyeballs that is radiating from the both corners to limbus. The patient was conscious and cooperative. Cranial nerves were intact. There were hypotonia which was more marked in lower limbs with diminished jerks and flexor plantar reflexes. Gait was wide based and ataxic.

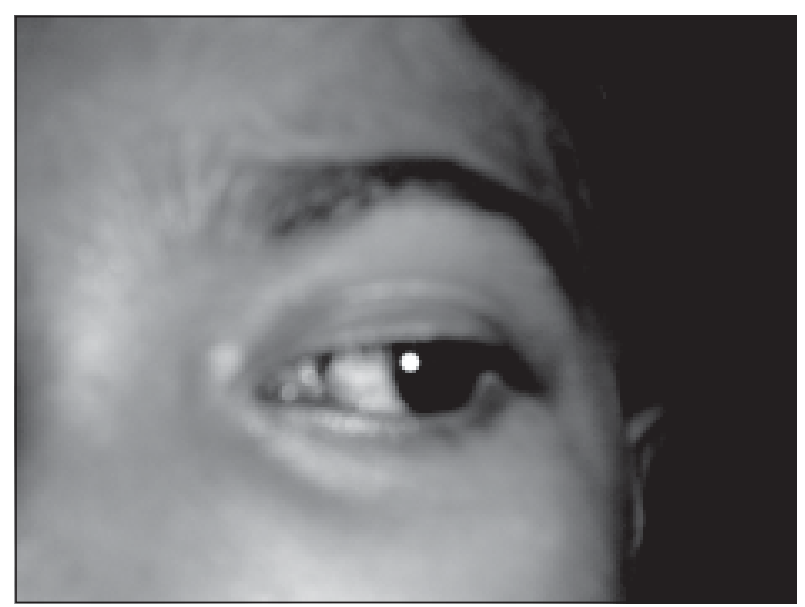

Fig.-2a: telangiectasia of conjunctivae

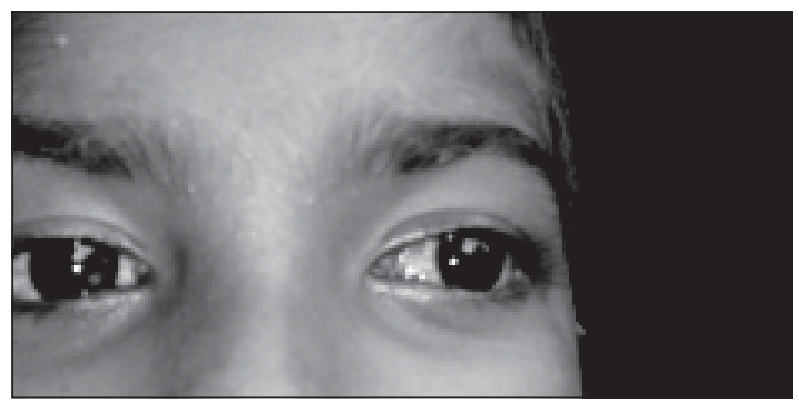

Fig.-2b: telangiectasia of conjunctivae

Sensory function was intact. Cerebellar function was abnormal showed nystagmas, slurred speech, intention tremor, past pointing and dysdiadochokinesia. On investigation, complete blood count, lipid profile, LFT, chst xray, serum electrolytes, ultrasonogram of whole abdomen and ECG showed normal results. MRI showed cerebellar atrophy. Serum $\alpha$-feto protein was $1350 \mathrm{ng} / \mathrm{L}$. MRI showed cerebellar atrophy that seemed as trifoliate. There was no specific treatment was provided for AT. Only the conservative treatment was advised to avoid respiratory tract infection. Physical and speech therapy was advised.

\section{Discussion:}

In general, Ataxia-telangiectasia (AT) is a multisystem disorder characterized by progressive neurologic impairment, Cerebellar ataxia, variable immunodeficiency, and ocular and cutaneous telangiectasia. Patients with AT have an increased susceptibility to sino pulmonary infection, x-ray hypersensitivity, and predisposition to malignancy ${ }^{13}$. A Previous 
studies have shown that in Iran investigators sought to characterize the clinical and immunologic features of Iranian patients with $\mathrm{AT}^{14}$. These patients with AT who had been diagnosed and treated at Children's Medical Center during a 20-year period (1985-2005) were analyzed. The study population comprised 104 patients (54 male). The median age of patients at the time of the study was approximately nine years. Clinical characteristics included progressive ataxia (100\%of patients) that was present in our case, telangiectasia of skin or conjunctivae $(83.8 \%)$ and of ears $(70.2 \%)$, eye movement disorder (apraxia of horizontal and vertical saccadic eye movements)(80.6\%),choreoathetosis(87.1\%),speech dysarthria in almost all and that is also present in Our patient .

Acute and recurrent sino pulmonary infections affected $75 \%$ of patients where our patient has been suffering from recurrent respiratory tract infections since birth. Our patient has Cerebellar atrophy on MRI that was appearing like trifoliate it was suggesting to the point of possibility of ataxia Telangiectasia. ${ }^{15}$ Average serum $\alpha$-fetoprotein level in study patients was elevated at $149 \mathrm{ng} / \mathrm{L}$ and in our case it is more than $1350 \mathrm{ng} / \mathrm{L}$. Elevated serum $\alpha$-fetoprotein level was described as a useful screening test for AT in 1972. ${ }^{16}$

\section{Conclusion:}

Ataxia Telangiectasia (AT) follows progressive course. It must be stressed that the course of the disease can be quite variable and it is difficult to predict the course in any given individual. Even within families, where the specific genetic defect is the same, there can be great variability in the type and severity of different neurologic problems and immunodeficiency. Many patients are confined to a wheelchair in their teens. Some patients have been able to attend college and live independently, and some have lived into the fifth decade of life.

\section{References:}

1. Boder E, Sedgwick RP. Ataxia-telangiectasia; a familial syndrome of progressive cerebellar ataxia, oculocutaneous telangiectasia and frequent pulmonary infection. Pediatrics. 1958; 21: 526-54.

2. Abraham RT. Cell cycle checkpoint signaling through the ATM and ATR kinases. Genes Dev. 2001; 15: 2177-96.

3. Lavin MF, Shiloh Y. The genetic defect in ataxia telangiectasia. Ann Rev Immunol. 1997; 15: 177202 .

4. Shiloh Y. ATM and related protein kinases: safeguarding genome integrity. Nat. Rev. Cancer. 2003; 3: 155-68.

5. Shiloh Y, Kastan MB. ATM. genome stability, neuronal development, and cancer cross paths. Adv Cancer Res. 2001; 83: 209-54.

6. Kastan MB, Lim DS. The many substrates and functions of ATM. Nat Rev Mol Cell Biol. 2000; 1: $179-86$.

7. Shiloh Y. ATM (ataxia telangiectasia mutated): expanding roles in the DNA damage response and cellular homeostasis. Biochem Soc Trans. 2001; 29: 661-6.

8. Barlow $\mathrm{C}$, et al. Loss of the ataxia-telangiectasia gene product causes oxidative damage in target organs. Proc Natl Acad Sci, USA. 1999; 96: 9915-9.

9. Reichenbach J, et al. Elevated oxidative stress in patients with ataxia telangiectasia.Antioxid. Redox Signal. 2002; 4: 465-9.

10. Reliene R, Fischer E, Schiestl RH. Effect of Nacetyl cysteine on oxidative DNA damage and the frequency of DNA deletions in atm-deficient mice. Cancer Res. 2004; 64: 5148-53.

11. Schubert R, et al. Cancer chemoprevention by the antioxidant tempol in ATM-deficient mice. Hum Mol Genet. 2004; 13: 1793-1802.

12. Kamsler A, et al. Increased oxidative stress in ataxia telangiectasia evidenced by alterations in redox state of brains from ATM-deficient mice. Cancer Res. 2001. 61: 1849-54.

13. Ball LG, et al. Molecular basis of ataxia telangiectasia and related diseases. Acta Pharmacol Sin. 2005; 26: 897-907.

14. Moin M, Aghamohammadi A, Kouhi A, et al. Ataxia-telangiectasia in Iran: clinical and laboratory features of 104 patients. Pediatr Neurol. 2007; 37: 21-8.

15. Sardanelli $F$ et al. Cranial MRI in ataxiatelangiectasia. Neuroradiology. 1995;37:77-82

16. Strober W, et al. Immunoglobulin metabolism in ataxia telangiectasia. J Clin Invest. 1968; 47 : 1905. 